\title{
LEARNING IN LIBRARIES
}
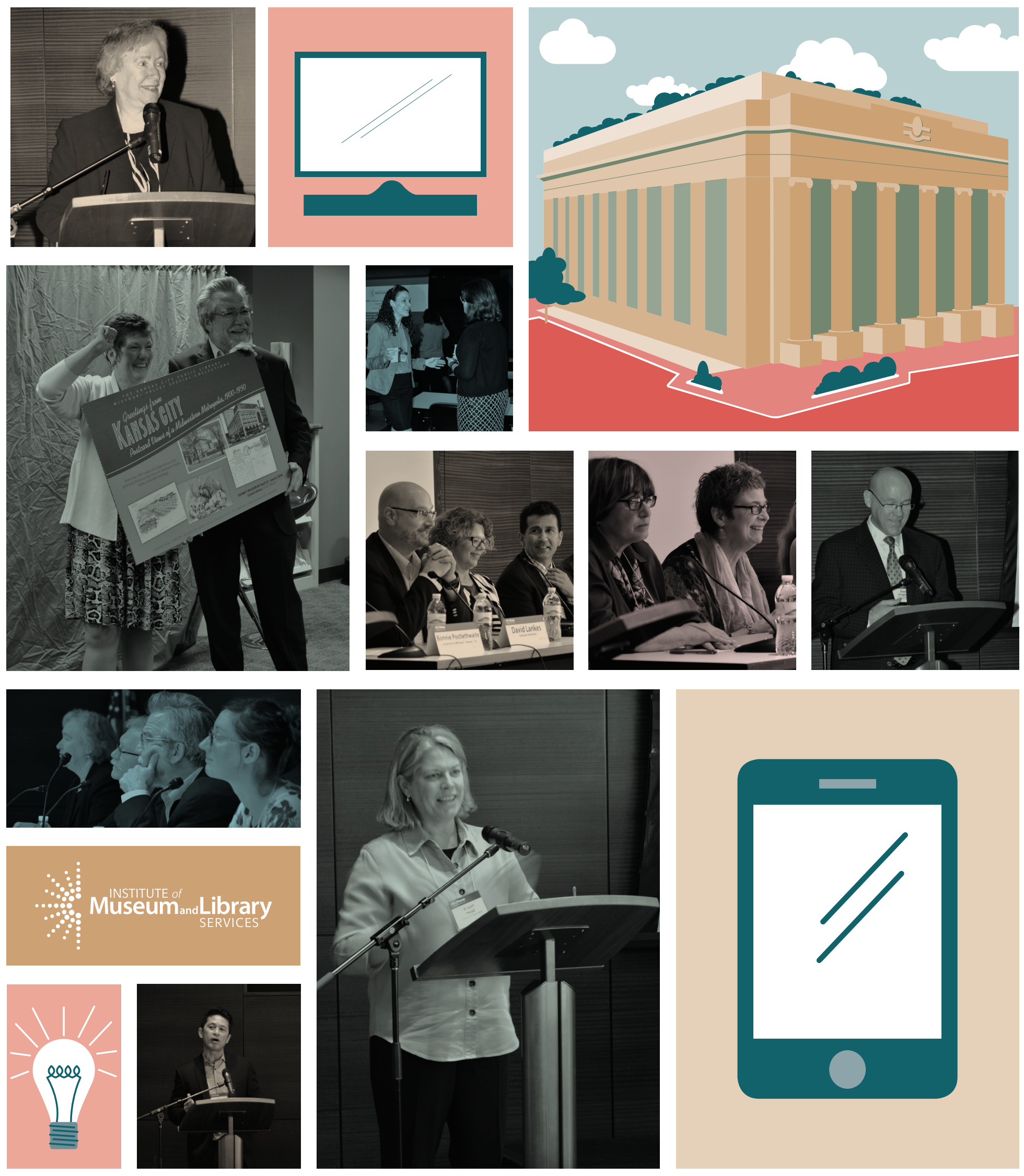
Thursday, May 14, 2015

Kansas City Public Library: Kansas City, Missouri

Compiled and edited by Chrystie Hill, Merrilee Proffitt, and Sharon Streams, OCLC 


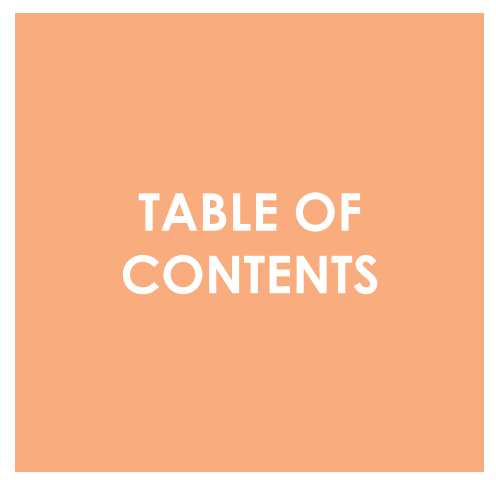

4 A MESSAGE FROM MAURA MARX, ACTING DIRECTOR

5 LIBRARIES ARE FOR LEARNING

6 PARTICIPATORY LEARNING: DOING, TOGETHER

7 EMBRACING THE EARLY LEARNING ECOSYSTEM

8 LEARNING FOR ADULTS: STRENGTHENING THE WORKFORCE

9 FROM PRACTICE TO RESEARCH TO PRACTICE

10 DIGITAL LITERACY AND INCLUSION

11 SHAPING THE PROFESSION

13 GOING FORWARD: KEY THEMES

14 APPENDICES 


\section{A MESSAGE FROM MAURA MARX, ACTING DIRECTOR}

Libraries have always been learning places. Yet there has been a shift in recent years, taking place in the types of learning experiences that libraries are offering their communities. This movement challenges us to better understand how to support learning, far beyond reading. We must consider not only how we offer these new learning experiences, but also how we, as professionals, learn in order to gain the expertise to do so. This shift reinforces our belief that libraries offer much more than access to books. For a young child in a hands-on making program, a teenager creating a video presentation, a new American learning English as a second language, or a senior sending their first email - libraries are natural partners in supporting individual learning objectives.

The Institute of Museum and Library Services (IMLS) aims to support and learn from the field's expertise as we implement our current funding priority of "Learning in Libraries." In 2012 and 2013, the agency partnered with the MacArthur Foundation to help plan and create 24 Learning Labs in libraries and museums across the country. Additionally, we've made key investments to help the field advance participatory learning opportunities. One such project brings together the Pittsburgh Children's Museum, San Francisco Exploratorium, North Carolina State University Hunt Library, Chicago Public Library, and the Maker Education Initiative to provide both library and museum professionals with a suite of tools and services, hands-on professional development experiences, and a community of practice that will disseminate resources for field-wide replication. We're deeply interested in the experiences that library professionals on the front lines are having in delivering similar experiences to their communities.

Meanwhile, we continue to work to strengthen core learning services in libraries. In the area of early learning, we've partnered with Reach Out and Read on "Prescription for Success," a one-year project that will utilize the medical community to help more families benefit from museum and library services that foster literacy development in young children. In the area of adult learning, IMLS and the U.S. Department of Labor are working together to highlight effective practices in the workforce investment system and in public libraries. We also collaborate with U.S. Citizen and Immigration Services to help libraries provide accurate and useful information about immigration and citizen benefits, while promoting awareness of all kinds of resources available to new Americans.

As we move into a new funding cycle, IMLS is less focused than in the past on supporting specific types of learning or learning spaces. Instead, we aim to build on past initiatives to help libraries and the profession best evaluate and support their communities' specific learning needs. We are interested in projects that support local or distributed learning, and which have the greatest potential of having broad national impact. These projects might include methods of assessing needs, training or implementing learning services, which could be effectively utilized by other libraries across the country.

As we gathered at the Kansas City Public Library in May for our Focus on Learning in Libraries convening, we were thrilled to welcome representatives from some of our recent investments, as well as colleagues from the American Association for School Libraries, the Association of Research Libraries, the Coalition for Networked Information, Chief Officers of State Library Agencies, academic research institutions and information schools, among others. More than 400 participants joined us online for the live webcast, now archived at www.imls.gov, and live tweeted the event under the hashtag \#IMLSfocus.

We hope this report captures some of that rich conversation of that gathering. The 2015 IMLS Focus convening series was designed to facilitate a national conversation about shared priorities. We're most grateful to all who contributed and participated.

Maura Marx

Acting Director, IMLS 
LIBRARIES ARE

FOR LEARNING

Through the collections, services, and spaces they provide, libraries offer us a lifelong opportunity to gain the knowledge, skills and experiences that will enrich our lives. With the increased availability of online resources, libraries are now positioned to re-imagine services and spaces, to increase their reach to and impact on the communities they serve.

IMLS has funded diverse learning-based projects, from ones that explore new hands-on tools such as those in makerspaces, to ones that strive to meet the literacy needs of families with young children, to ones that help adults develop the job skills that will make them competitive in today's economy. This work has been funded from both the practitioner and researcher perspectives, with a goal to improve individual and community outcomes. The agency's most recent investments have aimed to build and sustain the capacity for libraries to adopt research-based

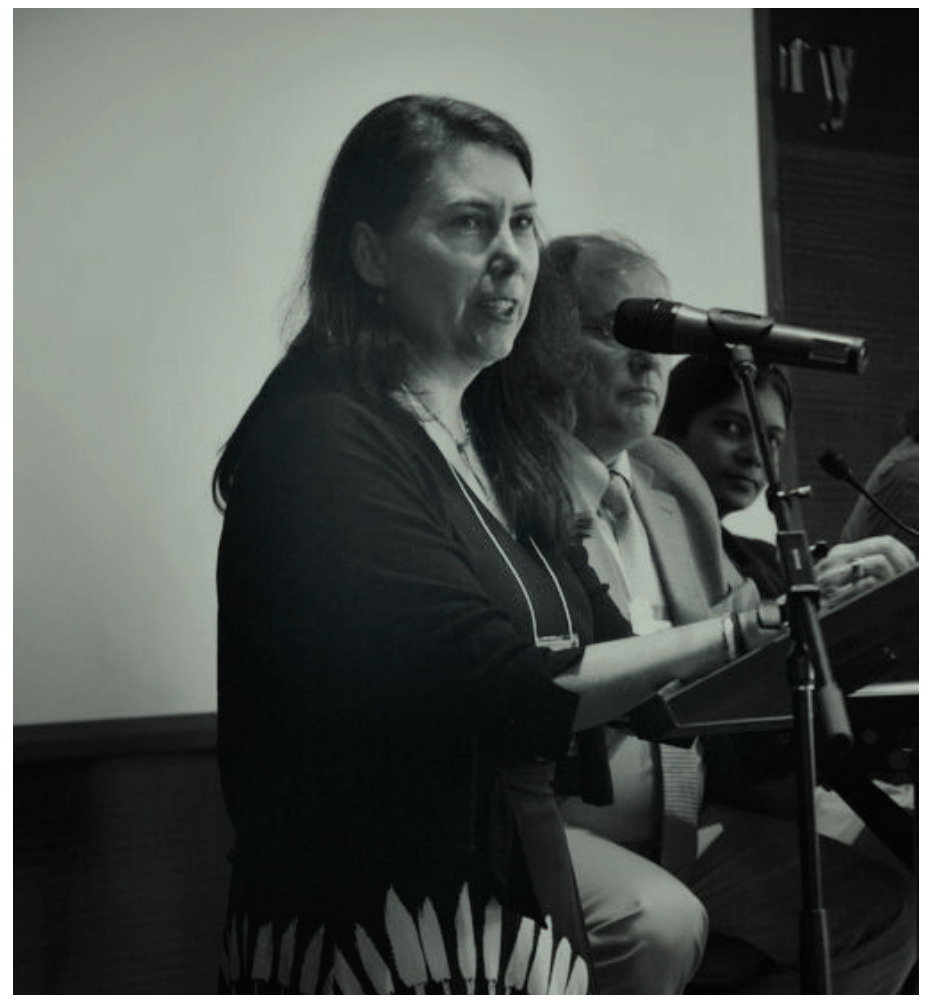

Above: Jill Castek, Portland State University Right: Learning in Libraries attendees practices and to encourage the formation of sustainable partnerships with organizations at the local, state, regional, and national levels.

In May 2015, IMLS convened public and state library practitioners, library and information science school representatives, researchers, service providers, and allied organizations at Kansas City Public Library for a daylong forum on learning in libraries. Representatives of recent IMLS investments in participatory learning, early learning, adult learning, digitally inclusive communities, research, and continuing education gathered to share their challenges, outcomes, and suggestions for future focus.

This document summarizes the day's presentations and discussions and documents for both IMLS and the community the themes and recommendations that emerged for funding priorities to advance learning in libraries. These recommendations are summarized at the end of the report; the agenda and participant list are included as appendices.

If there's anything we're trying to do in this library and the library world, it is to build a learning culture. The achievement gaps are getting bigger, the access questions are getting bigger, but the most important thing is...the creation of an imaginative world for children and...adults that opens their minds to the world. - Crosby Kemper, Kansas City Public Library

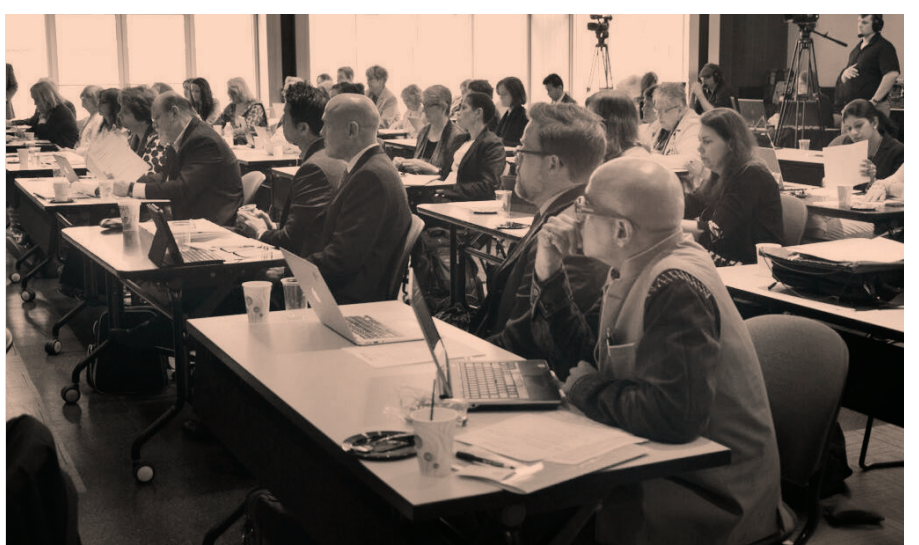




\section{PARTICIPATORY}

LEARNING: DOING, TOGETHER

Joan Lippincott, Associate Executive Director, Coalition for Networked Information, defined participatory learning as a practice that "...emphasizes two important aspects of the learning process which many educational researchers say leads to deeper learning. They are first, active learning-doing-not just passively absorbing the content of a subject; and second, the notion that learning is a social process." Tod Colegrove, Director, DeLaMare Science and Engineering Library, University of Nevada, Reno, gave examples from an academic science and engineering academic library that illustrate that definition. Library spaces and tools support both the physical aspects of learning through hands-on practice as well as the social aspects of learning. This combination, Colegrove believes, has been transformative. "After three years of working with a model on a two-dimensional screen, [and now] using three-dimensional modeling software, within thirty seconds of handling the physical printout and turning it over, a faculty member realized something he would have never been able to do [before]. In his estimation, he shaved five years off of his research."

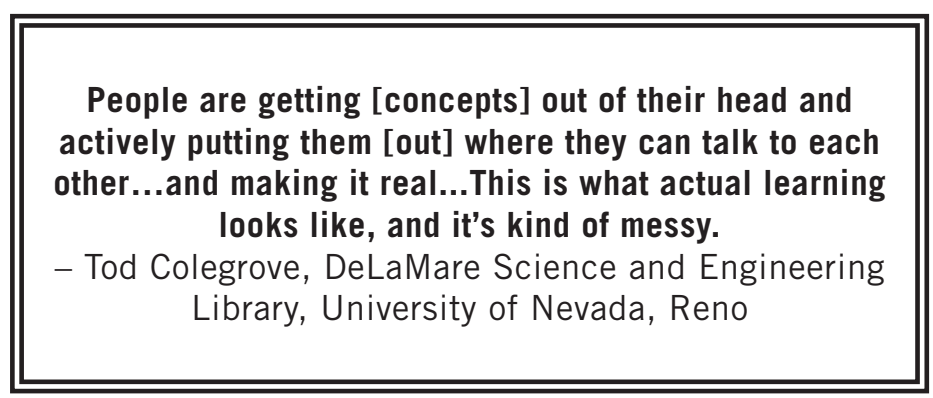

Bill Derry, Director of Innovation, Westport Library, described how their makerspace project transformed the library from a place of consumption to a place of production, attracted new audiences, and engaged community support for new services that ranged from coding workshops to creating 3D models to help teach math concepts to the blind. As the makerspaces attracted participants and mentors of all ages, the library increased its understanding of the approach to and value of intergenerational programming. "It's more about experience and knowledge than it is about degrees and awards."
Laura Damon-Moore is co-creator of the Library as Incubator Project, which is a story-telling platform that highlights art making in libraries. She gave examples of incubator projects that demonstrate trends that have emerged in the last couple of years in participatory learning-based library programs. These include development of meaningful and sustainable library-artist partnerships; support for self-directed research and learning for design students; opportunities for real-work application of learning and professional networking for youth; and programs that make use of the library's collections rather than just its hosting space.

The shift to supporting participatory learning can pose challenges, but that transition is more easily achieved when library staff move to a participatory mode of working. It is essential for library staff to have time to get their own hands dirty with the learning tools that patrons will be using, and to understand that what may seem like playtime actually is the work.

We put "play" into our monthly reports as a category ... that was just a way for us to focus on the fact that ... we need to make room for it. - Bill Derry, Westport Library

Stories of transformation due to participatory learning experiences don't fit easily into libraries' quantitative forms of measurement. Qualitative practices may prove a better fit for recording outcomes, and need to be thoughtfully planned during the design phase. Joan Lippincott suggests that we "think very broadly about assessment ... it isn't just about the numbers...Turn anecdotes into case studies and do it more systemically. Do a genuine study, capturing voices and interviews, and get that data."

During the discussion, participants raised the question of how to extend participatory learning outside of the library, to schools, the neighborhoods, and elsewhere. Panelists described bringing portable maker kits to schools, senior centers, neighboring communities; hosting or participating in "Maker Fairs" at the local, state or national level; connecting with other maker spaces; and, essentially, bringing learning to where the community members are, whether it is inside or outside the library. 
EMBRACING THE

EARLY LEARNING ECOSYSTEM

Clara Bohrer, Director, West Bloomfield Township Public Library, set the stage for a discussion on early learning in libraries by underscoring the strong investment that IMLS has made in this area since 2013, including the Growing Young Minds report. She also placed the work of libraries within an ecosystem that includes families, communities, educators, early learning systems, social service providers, policy makers, funders, and more-underscoring the need for these entities to work together to drive collective impact.

Diane Hutchins, Consultant and Project Manager, Washington State Library, described a University of Washington iSchool study, Project VIEWS, which showed that through intentional practice, library storytimes affect the development of young children's early literacy skills. This research informed the development of a suite of tools and resources for practitioners that is being piloted across Washington and five other states, in partnership with OCLC. She encouraged investment in projects that (1) support collaboration and understanding among libraries and with early learning specialists through intentional partnerships; (2) conduct early learning research, including the linkage of library best practices to state early learning standards; and (3) provide needs assessments and outreach strategies to understand how to engage and support parents, caregivers, and other early learning providers.

\section{An announcement came out a few weeks ago for an early} learning conference: Who should attend? Professionals who care for or work with young children and parents. Well, the list covered a wide spectrum of disciplines and providers. Guess which group was missing as usual? Librarians. - Diane Hutchins, Washington State Library

Beth Crist, Youth and Family Services Consultant, Colorado State Library, shared information on Project SPELL, which was designed to engage low-income families with young children in early literacy programs. The project produced a blueprint that other projects could use for staff training in cultural proficiency, space design, collections, programs, policies, and customer service. Crist echoed Hutchins' call for partnerships that will not only extend services to existing audiences, but help libraries reach and serve target communities. Crist spoke about motivations for fostering partnerships to extend library services outside and beyond the library. "We know that not all parents will be able to come to the library, right? So we have to do a better job of promoting and getting out to work with organizations to partner and collaborate." The list of partners that collaborate on Crist's project demonstrates the breadth of possibilities available outside the library: "Some of the partners these eight libraries are working with are a Native American tribe, a migrant program, subsidized child care centers, the local United Way, and parenting groups - and these are having significant impacts. These groups already work with the lowincome populations...When the library connects, it makes such a difference."

Panelist Kathleen Deerr, National Coordinator, Family Place Libraries at Middle Country Public Library, described the "family place library" model, which is rooted in the notion that the family is the constant in a child's life and has the most impact on early development; therefore, the library places great emphasis on creating a strong network of community support for families. In developing library services that support and engage parents, some key elements emerged. First, "libraries need to develop non-judgmental, welcoming, permanent spaces...We want everybody to be there." Second, programs should meet the needs and interests of parents, as well as the children, and help parents form supportive relationships with one another. To this end, Family Place Libraries partner with social organizations, health and human service organizations, and museums. Deerr sees opportunities to further build library staff skills and capacity through more such partnerships, recommends support for expanding successful home visit programs, and advocates for additional research for reaching young children with disabilities.

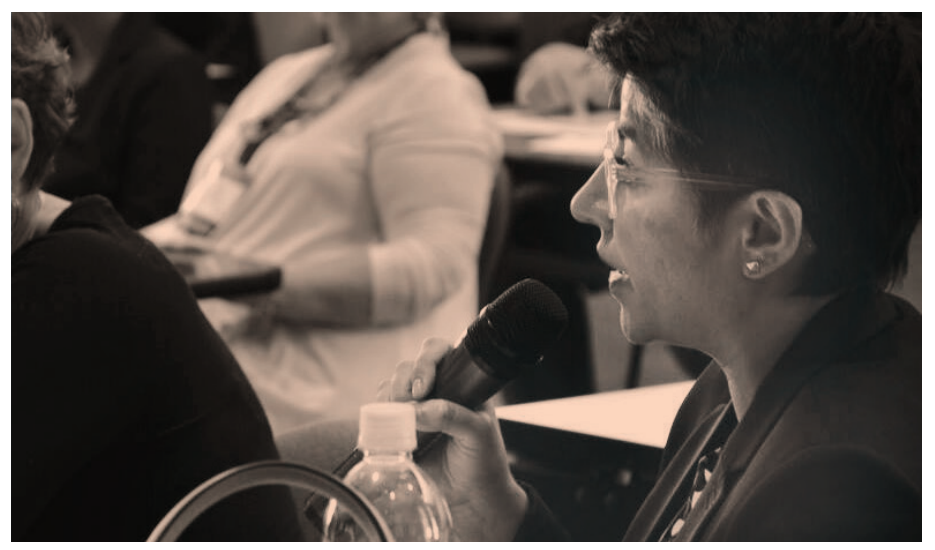

Above: Andrea Saenz, Chicago Public Library 
Themes that were raised in the sessions on participatory learning and early childhood education - that is, reaching expanded audiences and the importance of partnering with community organizations-were echoed in the session on adult learning. In her presentation on serving the adult education needs of immigrant communities in Rhode Island, Karisa Tashjian, Literacy Program Coordinator, Providence Public Library, observed that even when libraries design services with particular audiences in mind, they may not be effectively reaching those groups on their own. "[P]eople who don't come into the library - why are they not coming in? How can we reach out to them and bring them in? The barriers are much deeper than I ever realized." Tashjian went on speak to the extended reach provided by partnerships. "I can't be in all of those rooms, but all of our partners are in those rooms, and they're speaking up on our behalf." Tashjian noted that working with partners takes patience and requires becoming fluent in a new set of jargon.

The recently passed Workforce Innovation and Opportunity Act of 2014 offers an opportunity for libraries to take unified action to raise their visibility as agents of workforce development: "Right now, [your states are] required to develop unified plans on how they're going to work together for workforce development. I want to ask the question: how many libraries are...in the conversations? I've been knocking on the door and it's really hard." Tashjian suggests that libraries should have a strategy for getting a meaningful place at the table where relevant discussions are happening.

Diosdado Gica, Director of Learning and Literacy, Queens Borough Public Library, spoke about the challenges of providing adult learning services to a very large immigrant population. By placing adult education at the forefront, the library has formed strategic partnerships that allow services to scale and sustain despite limited city funds. IMLS funds were used to develop a curriculum and train more than 400 librarians on immigrant services; and departments have been integrated to combine adult learning and literacy with workforce development and legal services.

Cindy Gibbon, Access and Information Services Director, Multnomah County Library, talked about their project aimed at helping patrons acquire the skills needed to be employable in today's work world. The project will measure the literacy, numeracy, and problem-solving skills of workforce-age adults, thus creating a body of baseline data that will inform library services. Gibbons observed that public libraries need staff with a wide range of skills. "We need folks who are experts in early childhood education... who are experts in adult education and workforce development... who know how to assess the needs of their community, who know how to create partnerships in their community in order to bring resources together."
The goal here is to really reach out to people who are struggling and who may not be finding a place in the workforce. Why do we do this? Because we want to understand what our patrons need to learn to thrive in this technology-rich world that we live in.
- Cindy Gibbon, Multnomah County Library

Following the panel session on adult learning, Anne Craig, Director, Illinois State Library, Timothy Cherubini, Executive Director, Chief Officers of State Library Agencies, and Chrystie Hill, Community Relations Director at OCLC and representing the Coalition to Advance Learning in Archives, Libraries, and Museums, each spoke to the benefits of crossing local, regional, and industry sector boundaries to offer learning for library staff at scale. Cooperative projects, cross-sector initiatives, and national associations were highlighted as essential means for bringing individual and institutional learning into broader application across the country.
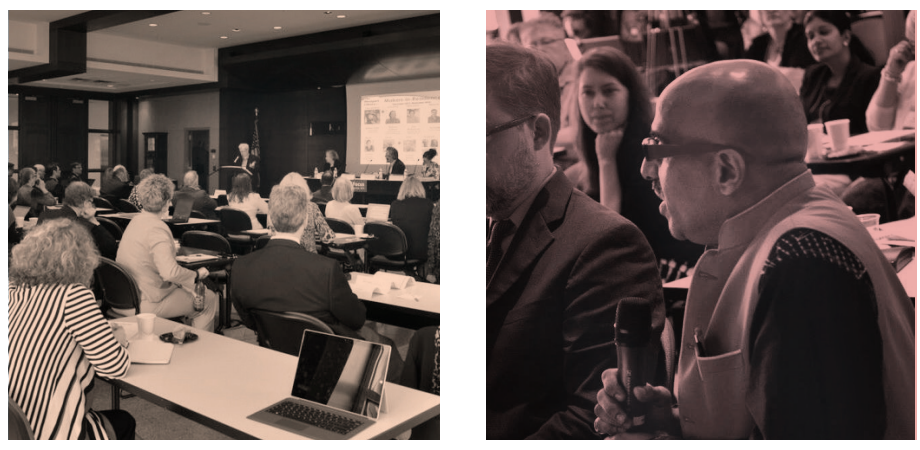

Top Left: Learning in Libraries attendees Top Right: Bharat Mehra, University of Tennessee, Knoxville 


\section{FROM PRACTICE}

TO RESEARCH

TO PRACTICE

IMLS fills an important role both in funding projects based in practice as well as funding "pure" research that largely takes place in library schools. Over the course of the discussion, practitioners and researchers explored the need for bridging the gap between research and practice.

It's really important to be able to include researchers in practice, and similarly, inclusion of practitioners

in research.... Researchers and librarians cannot be developing learning environments, innovations, continuing education programs in isolation, or separation from each other.

- Mega Subramaniam, University of Maryland, College Park
Not only should projects actively make the transfer of knowledge between research and practice as effective as possible, but shared investigation should ideally incorporate researchers from areas that complement our own field. Mega Subramaniam, Assistant Professor, iSchool - College of Information Studies, University of Maryland, College Park, urged us to consider input from "areas that are critical for learning, such as public policy, learning sciences, English as second language, digital media. We are merely touching the surface in investigating the learning that happens in libraries." Given the enormous acceleration of change faced by libraries of all types (characterized by Alison Head, Principal Research Scientist, Information School, University of Washington, as disruptive change in the education sector that includes "flipped classrooms, ubiquitous technologies... and the change in power structures"), both researchers and practitioners should be open, and even eager, to explore the outer boundaries of what is considered to be current practice.

Participatory design or design-based implementation research methods might yield more rapid iteration, for both project design and implementation. Subramaniam said that this mode of work allows "researchers and librarians to work together more closely...so the process is really iterative and the goal is continuously to refine and develop the learning program or technology."
[The funding that] IMLS is putting forth is at the frontier of expanding library services and outreach programs in the community, and it's up to us to use these funds to build these collaborative partnerships that maximize resources and extend impact and sustainability. - Jill Castek, Portland State University

Panelists urged grantees to think about the dissemination of findings right from the beginning, in order to maximize impact. Jill Castek, Research Assistant Professor, Portland State University, said that it is important for research to be "designed strategically from the very beginning... and that means thinking about dissemination at the outset of every project design, not as an afterthought." Castek's IMLS-funded project convened an advisory group comprised of practitioners to advise on how best to achieve not just dissemination of findings, but uptake in the field: "So... it wasn't just, bam, here is a research article, please go out and implement this. Instead, it was a context and a conversation, which becomes responsive to how the field needs to frame their understanding before the findings come out." John Horrigan, Senior Researcher, Pew Research Center, encouraged focusing on creating a "pathway to influence" and finding a way of getting research outcomes to where they will make a difference to decision makers.

Discussion participants also encouraged a broader notion of what is worthy of dissemination, encouraging grantees to be more bold in sharing unexpected findings, failed research, and what didn't work. "Truthfully," said Marcia Mardis, Associate Professor, Coordinator, Educational Informatics, Florida State University, "it would inform our field a whole lot more if we saw a whole lot more of those results." 
Digital inclusiveness remains a critical and complex area for libraries. Without access to information and communication technology (ICT), nearly every aspect of American societyfrom economic success and educational achievement, to positive health outcomes and civic engagement-is compromised. Addressing the "digital divide" between those who have access to ICT and those who do not includes ensuring that individuals take advantage of the significant educational, economic, and social opportunities that are now available via ICT.

Dwight Mclnvaill, Director, Georgetown County Library, spoke about the challenges of representing undocumented communities. His library is partnering on a project, "Out of the Rice Fields: Vestiges of Gullah Culture in Modern Society." The Gullah project is documenting the history and culture of this local culture through oral history and through physical and virtual exhibits of community images and documents. Mclnvaill also discussed barriers to access in rural settings. "[Y]ou can't assume that people will come [to your library], particularly in rural areas where transportation is a huge problem...You have to go to them."

In 2006, Ruth Small, Laura J. \& L. Douglas Meredith Professor, School of Information Studies, Syracuse University, conducted a survey of 1,600 school library staff in New York State. The survey showed that $84 \%$ of respondents did not feel adequately prepared to serve students with disabilities. Further investigation indicated that school librarians did not receive training or professional development in this area, which was the impetus for Project ENABLE, a training program on services to people with disabilities. Small championed the universal design approach as the way forward: universal design principles give practical guidance for how to select and arrange furniture and other library equipment so that the library is accessible to all; for example, how to position table height and spacing to accommodate people with mobility issues. "We don't normally think about those things," Small said, "but they keep other people from participating."

Colin Rhinesmith, Assistant Professor, School of Library and Information Studies, University of Oklahoma, speaking on behalf of Susan Feller, President/CEO of the Association of Tribal Archives, Libraries, \& Museums, touched on the great potential to make significant advancement toward addressing the digital divide on tribal lands. As broadband capacity increases, tribal and state libraries must be prepared to meet the growing demand for ICT and digital literacy training. A digital inclusion summit that will take place in Washington, D.C., this fall will bring together tribal librarians and leaders with funders, federal agencies, and other stakeholders to work together to ensure the best possible digital inclusion programs for native communities. Topics to be addressed may include training, E-rate, library loans, summer reading, and broadened access to subscription databases.
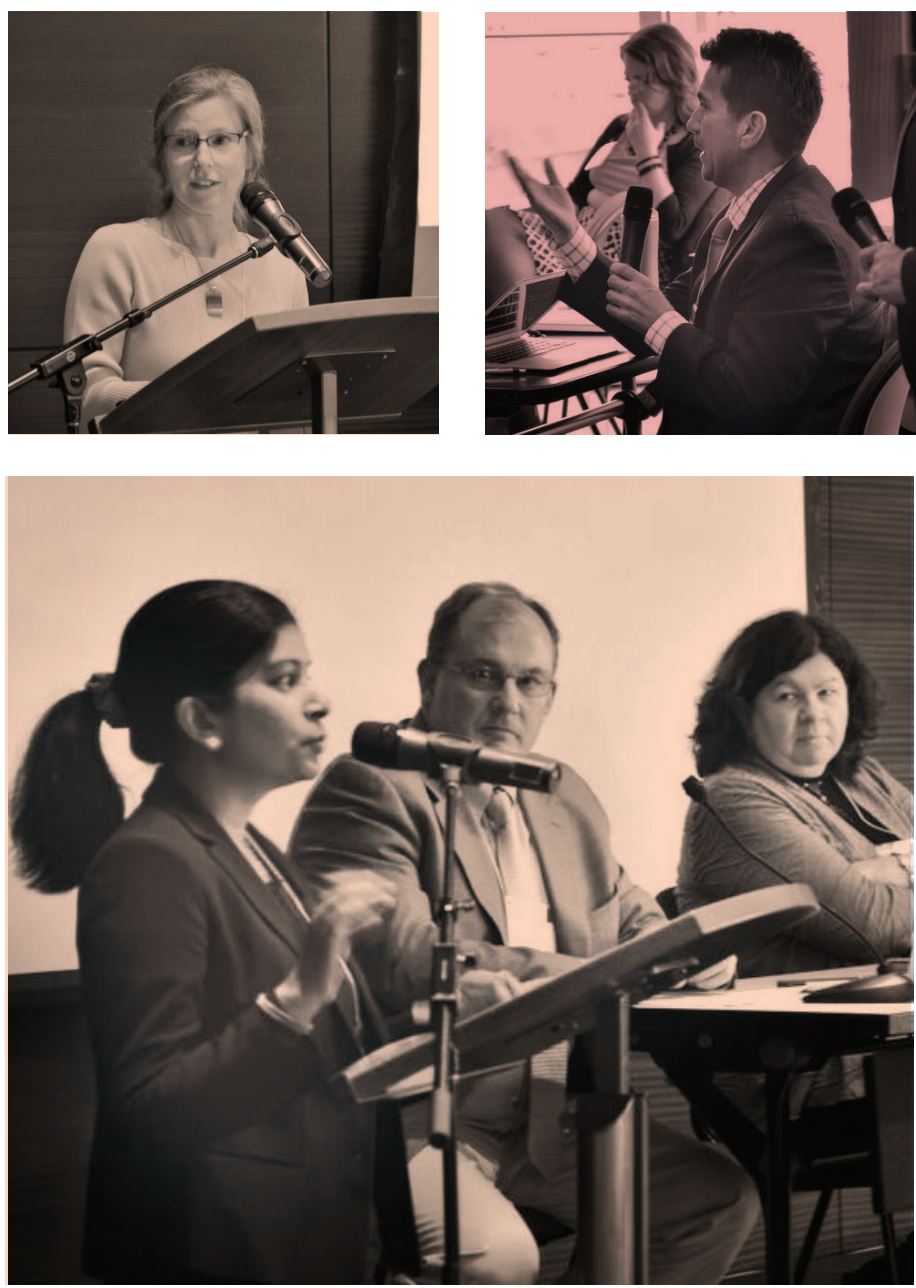

Top Left: Beth Crist, Colorado State Library

Top Right: Mark Puente, Association of Research Libraries

Bottom: Mega Subramaniam, University of Maryland,

College Park; John Horrigan, Senior Researcher, Pew

Research Center; Gail Dickinson, Old Dominion University 


\section{So how do you address a profession that is cradle-to-grave in service? How do you address a profession that crosses the economic spectrum from poor to absolute wealth? \\ - Siobhan Reardon, Free Library of Philadelphia}

Libraries serve a broad range of communities and audiences; discussions on the future of librarianship and how to shape the profession going forward was a theme throughout the day. Threads included the pressure for library professionals to have an ever-expanding set of skills and knowledge to engage and support user communities; moving from continuing education to continuous education, where practitioners' experience is fed back into LIS program curriculum; and the need to more intentionally address diversity and inclusion issues in our workforce.

[W]e need to move to a continuous education model where our alums teach our current students, our current students teach our professors.

- David Lankes, Syracuse University

The sheer breadth of competencies that library workers are called on to develop was expounded upon. Mark Puente, Director of Diversity and Leadership Programs, Association of Research Libraries (ARL), gave a sampling of skills included in recent $A R L$ job postings that ranged from digital curation to digital storytelling, from assessment to alternative metrics, from open data to open education, and more. In addition to specialized skills, there is also a long list of mind-set or dispositional qualities that have been articulated for the profession, such as "collaborative," "entrepreneurial," and "risk-taking."

The question of whether it was possible to train the "universal librarian" was discussed, with panelists suggesting that it was not possible. As David Lankes, Professor, School of Information Studies, Syracuse University, put it, "If we expect librarians to do everything, then they will do nothing well." Competencies help collect all potential skills, knowledge, and mind-sets that the profession may need overall, but organizations should prioritize. Siobhan Reardon, President and Director, Free Library of Philadelphia, asked "How do we stop being all things to all people? We can't. We can't afford it. We're not good at it, and so let's narrow down the skill sets in our strategic plan."

[We should consider what is] the most useful container for indicating that someone is prepared to enter the profession, whether that be a bachelor's degree, a master's degree, certificate, trying to understand what is valued about advanced education in library science, valued to the community, valued to the profession. - Mary Stansbury, University of Denver

The need for specialized skills can either result in those skills being added to the typical librarian education portfolio and continuing education programs, or will lead to libraries hiring from outside the profession to meet those needs. Puente reported, for example, that many ARL libraries are hiring outside of the traditional MLIS degree program pipeline. As a way of navigating the waves of change in our profession, Lankes asserted the need for the end-user community to leverage the library as a platform to share its collective expertise. This involves library staff connecting with members of the community and empowering them in their areas of interest and expertise. Lankes commented, "I get frustrated because we think we can train ourselves to be anything and oftentimes miss the point: brilliant people are coming into our buildings every day."

Reardon described how that approach was applied to the Free Library's Words at Play early learning program. They hired local library coordinators who lived in and understood the neighborhoods the program was designed to reach. The coordinators helped the library identify the places and people in those neighborhoods: "We went to the nail salons, we went to the beauty salons, and we went to the barber shops, but it's people who know these communities who are helping us build the skill sets of our overall library staff." Reardon noted that the experience underscored that librarians did not see themselves as the community leaders that they are. She added, "I really would love the library schools to ... take us from a place where we are a very passive profession to something that is very forward and very assertive and almost aggressive, to the point where we absolutely are 
community leaders, and here's why: We have a presence and we have a practice."

A call to make the library workforce more diverse was issued by Puente. He asserted that it is critical to begin discussing and educating the profession in both LIS programs and continuing education about the value that diversity and inclusion bring to our profession. He cited the reasons: when people see themselves represented in library collections, professional staff, and programming, there is increasing evidence that this adds to student success and advances the teaching and learning missions of the organizations. There is abundant scientific evidence that having a diverse workforce and diverse collections improves organizational performance. Puente also pointed out that addressing diversity and inclusion issues will counter the persistent problem of the systematic barriers that confront people from historically underrepresented or marginalized communities.

Puente also raised related issues to explore further: Are there conversations happening around recruitment of people with disabilities in our workforce? Are we accommodating them and finding appropriate roles for them, in whatever capacity, as advisors and professionals in our organizations? If that is not happening, what do we need to do to initiate those conversations?

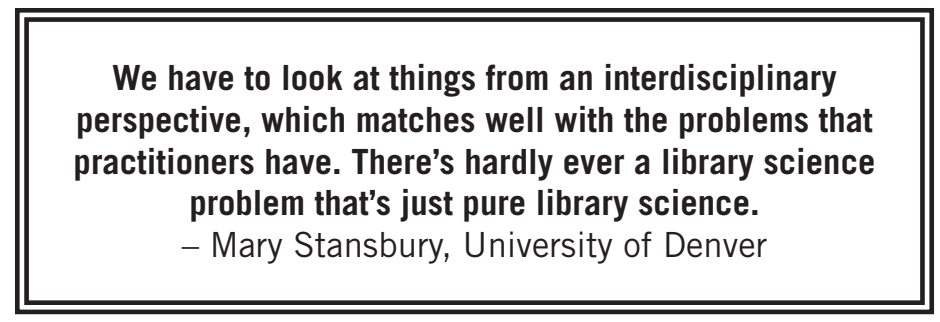

A discussion on how library schools and continuing education can best support the profession highlighted the interdependent relationship among MLIS and iSchool programs, their students, libraries, and end users. Lankes averred that "I don't believe that our communities are our customers. I believe that we are our communities. And just as when I talk about libraries and library science professors and library science students, I don't look at them as separate categories. I look at them as part of a profession." Suggested approaches for how schools and continuing education can be better integrated into the holistic community included mentoring, specializations, interdisciplinary programs, and opening up the criteria for library professional credentials. 
GOING FORWARD:

KEY THEMES

During the day's proceedings, four overarching themes emerged, which are offered as guidance to IMLS and potential grant applicants as recommended areas of focus for advancing learning in libraries.

\section{CONNECT LIS EDUCATION AND PROFESSIONAL DEVELOPMENT TO 21ST CENTURY LIBRARIANSHIP}

Library and information schools should reflect the evolving needs of $21^{\text {st }}$ century libraries and communities. Continuing education should be informed by other sectors and disciplines, and support librarians' mastery of new skills that will encourage learning in libraries, such as project management and partnership development. There is real potential for change in our institutions, when staff are encouraged to create and think in new ways about space and services. Apply participatory learning approaches toward professional development; provide students with hands-on experiences that complement their classroom instruction. We need best practices for diversifying our own workforce; broadening our ethnic makeup, languages spoken, and breadth of skill sets; and embedding librarians in community organizations.

\section{PURSUE RESEARCH THAT CONNECTS WITH LIBRARY PRACTICE}

Conduct relevant research on learning in libraries that both informs, and is informed by, practice. Develop mutually beneficial relationships between researchers and practitioners before a project is implemented, ideally at the design phase. Communicate research findings in ways that will lead to demonstrable improvements in library services. Find ways to ensure that new practices are easily adoptable, more affordable, and widely implemented. Design projects so that findings can be released iteratively, rather than at the conclusion of a project; and when possible, use existing data sources. Research dissemination should optimize impact and influence. Resulting outputs and data should be shared, including the unexpected and failed research. Extend what has been learned locally to other individuals, institutions, communities, states, and across the nation.

\section{DESIGN PARTICIPATORY LEARNING PROGRAMS THAT DEMONSTRATE INNOVATION AND SCALABILITY}

Design and develop new library programming models that provide participatory learning experiences for patrons across the lifespan. Possible audiences might include, but are not limited to, young children and their families; teens and tweens; un- and underemployed adults; and senior citizens. Meaningfully include the underserved and underrepresented. Implement intentional strategies for broad dissemination and scaling up rather than single local implementations. Demonstrate the efficacy of programs through evidence-based program evaluation.

\section{DEVELOP CROSS-DISCIPLINARY COLLABORATIONS THAT ADVANCE LIBRARY SERVICES NATIONWIDE}

Engage in mutually beneficial national partnerships with allied organizations beyond the library sector with the potential to broadly elevate the role of libraries and expand library services to new audiences. We need to expand our notion of the communities we serve, making sure that universal, inclusive design principles result in services that meet the needs of those we may not see in our buildings on a regular basis: the underserved from all ages, ethnicities, socio-economic conditions, and locations, and those with varying abilities and disabilities. More research is needed for reaching historically underrepresented or marginalized groups. People want to see and hear themselves reflected in library staff and service.

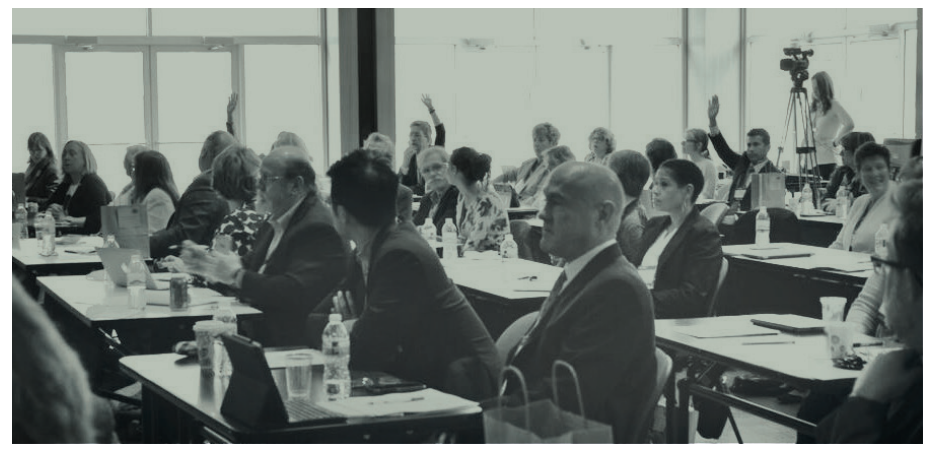

Above: Learning in Libraries attendees

Readers can view each panel and discussion session of the IMLS focus meeting on learning in libraries at www.tvworldwide.com/events/im/s/150514/; you can also

follow or join the conversation on Twitter using the hashtag \#IMLSfocus. 
8:30 - 8:45 a.m.

\section{Welcome and Opening Remarks}

- Speaker: Crosby Kemper, Executive Director, Kansas City Public Library, @KCLibrary

- Introduced by: Maura Marx, Acting Director, IMLS, @mauramarx / @US_IMLS

\section{$8: 45-9: 45$}

\section{Participatory Learning in Libraries}

- Moderator: Joan Lippincott, Associate Executive Director, Coalition for Networked Information, @cni_org

- Panelists:

Bill Derry, Director of Innovation, Westport Library, @BillDerry / @WestportLibrary

Tod Colegrove, Director, DeLaMare Science and Engineering Library, University of Nevada, Reno, @pcolegrove / @DeLaMareLibrary

Laura Damon-Moore, Co-creator, Library as Incubator Project, @LauraDM08 / @IArtLibraries

$9: 45-10: 45$

\section{Early Learning in Libraries}

- Moderator: Clara Bohrer, Director, West Bloomfield Township Public Library, @wblib

- Panelists:

o Diane Hutchins, Consultant and Project Manager, Washington State Library, @WAStateLib

o Beth Crist, Youth and Family Services Consultant, Colorado State Library, @BethCSL / @COStateLibrary

o Kathleen Deerr, National Coordinator, Family Place Libraries at Middle Country Public Library, @MiddleCountryPL

$10: 45-11: 15$

Break - Tour of the Kansas City Digital Media Lab

11:15 a.m. - 12:15 p.m.

Adult Learning and Workforce Development in Libraries

- Moderator: David Singleton, Director of Libraries, Charlotte Mecklenburg Library, @cmlibrary

- Panelists:

Diosdado Gica, Director of Learning and Literacy, Queens Borough Public Library, @QueensLibrary Karisa Tashjian, Literacy Program Coordinator, Providence Public Library, @ktashjian / @provlib Cindy Gibbon, Access and Information Services Director, Multnomah County Library, @MultCoLib

$12: 15-1: 15$

Working Lunch

\section{$12: 45-1: 15$}

Continuing Education for Librarians

- Moderator: Tim Cherubini, Executive Director, Chief Officers of State Library Agencies

- Panelists:

Chrystie Hill, Community Relations Director, OCLC, @itgirl / @OCLC

Anne Craig, Director, Illinois State Library, @annewbcraig

\section{$1: 15-2: 30$}

Leveraging Research to Inform Betfer Practice

Moderator: John Horrigan, Senior Researcher, Pew Research Center, @JohnBHorrigan 
Panelists:

Mega Subramaniam, Assistant Professor, iSchool - College of Information Studies, University of Maryland, College Park, @mmsubram / @iPAC_UMD

Gail Dickinson, Associate Dean, Graduate Studies \& Research, Old Dominion University, @gailkd/@ODUnow

Jill Castek, Research Assistant Professor, Portland State University, @Portland_State

Alison Head, Principal Research Scientist, Information School, University of Washington, @alisonjhead/@UW_iSchool

$2: 30-3: 30$

Digital Literacy and Inclusion

Moderator: Colin Rhinesmith, Assistant Professor, School of Library and Information Studies, University of Oklahoma, @crhinesmith / @OUSLIS

- Panelists:

Ruth Small, Laura J. \& L. Douglas Meredith Professor, School of Information Studies, Syracuse University, @drruthsyr / @iSchoolSU

Dwight Mclnvaill, Director, Georgetown County Library, @dmcinvaill / @GtownCoLibrary

Susan Feller, President/CEO, Association of Tribal Archives, Libraries, \& Museums, @TribalALM

\section{$3: 30-3: 45$}

Break

$3: 45-5: 00$

Aligning Curriculum with the Needs of Today's Libraries and Users

- Moderator: Bonnie Postlethwaite, Dean of Libraries, University of Missouri-Kansas City, @UMKCLibraries

- Panelists:

David Lankes, Professor, School of Information Studies, Syracuse University, @rdlankes / @iSchoolSU

Mary Stansbury, Associate Professor, Library and Information Science, University of Denver, @marystansbury / @UofDenver

Mark Puente, Director of Diversity and Leadership Programs, Association of Research Libraries, @ARLnews

Siobhan Reardon, President and Director, Free Library of Philadelphia, @FLPDirector / @FreeLibrary

5:00 - 5:15

Closing Remarks 


\section{APPENDIX B}

Attendee List

2015 IMLS Focus forum on Learning in Libraries

MARY ALICE BALL, Institute of Museum and Library Services

CLARA BOHRER, West Bloomfield Township Public Library

TIM CARRIGAN, Institute of Museum and Library Services

JILL CASTEK, Portland State University

TIM CHERUBINI, Chief Officers of State Library Agencies

TOD COLEGROVE, University of Nevada, Reno

ERICA COMPTON, Idaho Commission for Libraries

ANNE CRAIG, Illinois State Library

BETH CRIST, Colorado State Library

ROBIN DALE, Institute of Museum and Library Services

LAURA DAMON-MOORE, Eager Free Public Library

KATHLEEN DEERR, Middle Country Public Library

BILL DERRY, Westport Library

GAIL DICKINSON, Old Dominion University

ELYSE EIDMAN-AADAHL, National Writing Project

IXCHEL FANIEL, OCLC

SUSAN FELLER, Association of Tribal Archives, Libraries, \& Museums

SARAH FULLER, Institute of Museum and Library Services

CINDY GIBBON, Multnomah County Library

DIOSDADO GICA, Queens Borough Public Library

RACHEL GWANTLEY, National Summer Learning Association

ALISON HEAD, University of Washington

CHRYSTIE HILL, OCLC

JOHN HORRIGAN, Senior Researcher, Pew Research Center

DIANE HUTCHINS, Washington State Library

LARRY JOHNSON, New Media Consortium

CROSBY KEMPER, Kansas City Public Library

SYLVIA KNIGHT NORTON, American Association of School Librarians

JET KOFOOT, lowa Library Services/State Library

DAVID LANKES, Syracuse University

JOAN LIPPINCOTT, Coalition for Networked Information

CINDY LOMBARDO, Cleveland Public Library

MARCIA MARDIS, Florida State University

MAURA MARX, Institute of Museum and Library Services

DWIGHT MCINVAILL, Georgetown County Library

BHARAT MEHRA, University of Tennessee, Knoxville 
GREG MICKELLS, Madison Public Library

KATIE MURRAY, Institute of Museum and Library Services

TIMOTHY OWENS, Institute of Museum and Library Services

BONNIE POSTLETHWAITE, University of Missouri-Kansas City

MERRILEE PROFFITT, OCLC

MARK PUENTE, Association of Research Libraries

BARBARA READING, Missouri State Library

SIOBHAN REARDON, Free Library of Philadelphia

COLIN RHINESMITH, University of Oklahoma

ANDREA SAENZ, Chicago Public Library

DAVID SINGLETON, Charlotte Mecklenberg Library

KATHERINE SKINNER, Educopia Institute

RUTH SMALL, Syracuse University

HELEN SOULÉ, Partnership for 21 st Century Learning

MARY STANSBURY, University of Denver

MEGA SUBRAMANIAM, University of Maryland, College Park

KARISA TASHJIAN, Providence Public Library

SANDY THARP-THEE, lowa Tribe of Oklahoma

BETH YOKE, Young Adult Library Services Association 

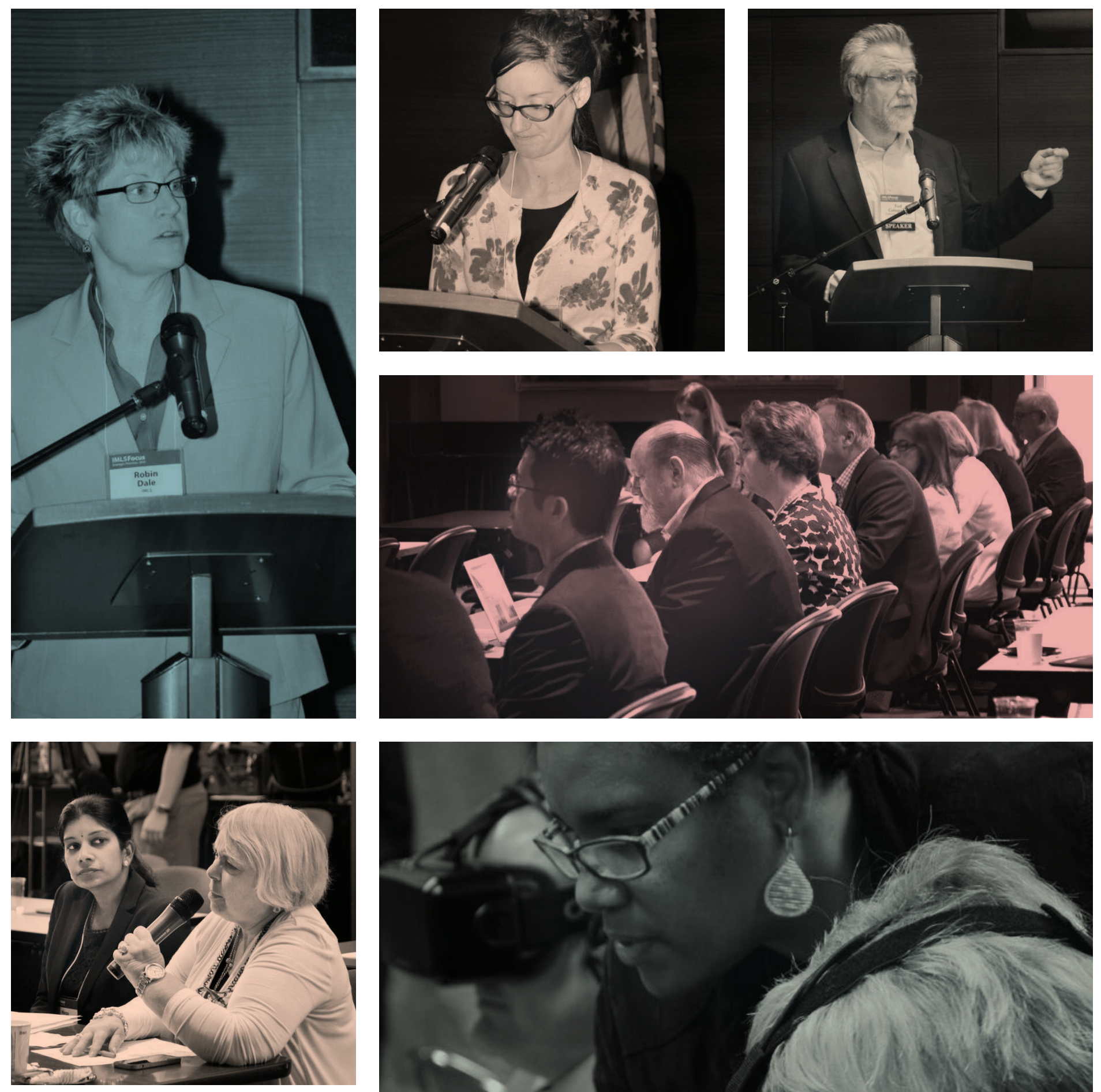

IMLS FOCUS

LEARNING IN LIBRARIES

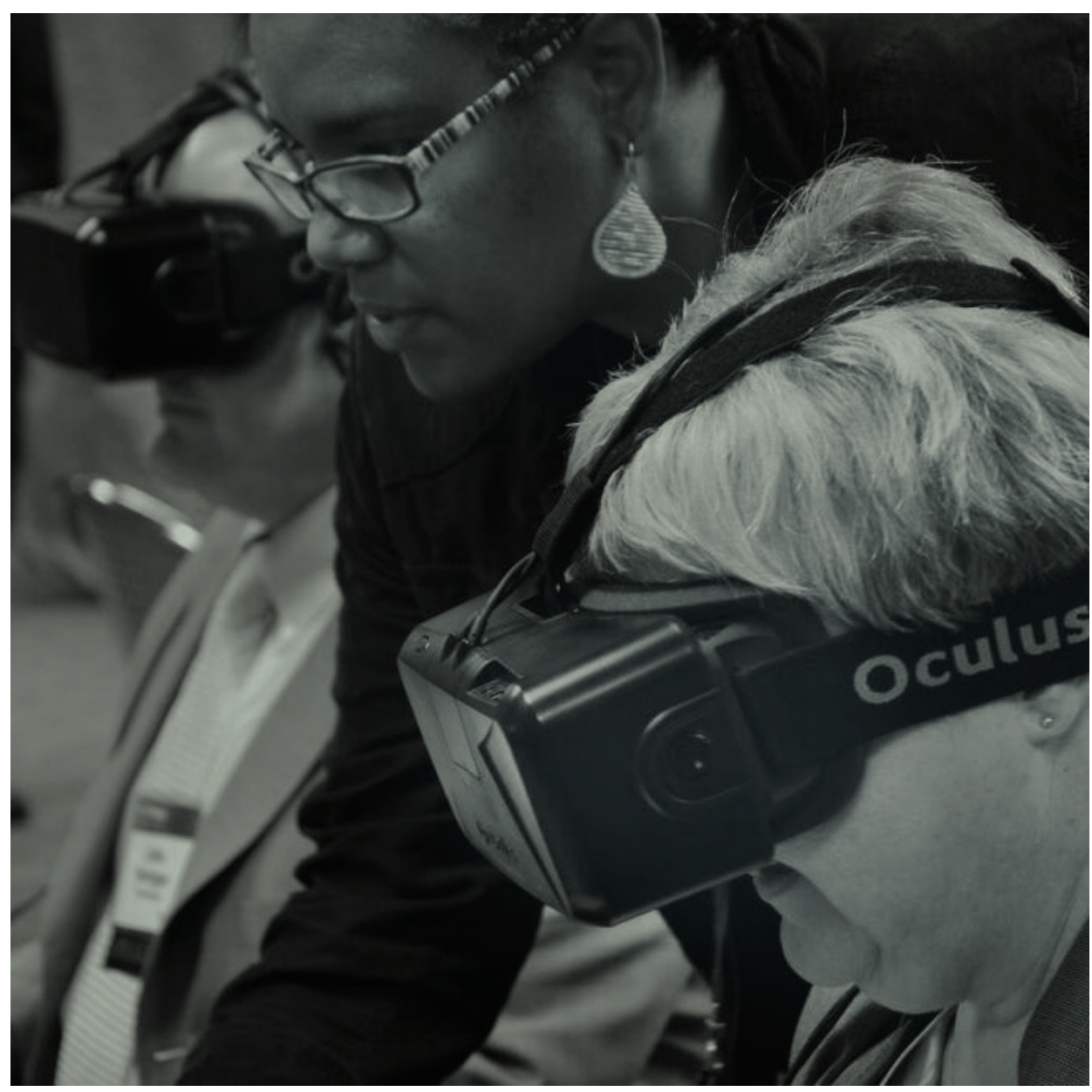

